\title{
Subsidizing New Technology Adoption in a Stackelberg Duopoly: Cases of Substitutes and Complements
}

\author{
Masahiko Hattori $^{1}$ • Yasuhito Tanaka ${ }^{1}$
}

Received: 16 May 2015 / Accepted: 19 February 2016 / Published online: 2 March 2016

(C) Società Italiana degli Economisti (Italian Economic Association) 2016

\begin{abstract}
Economic growth requires that firms adopt new technologies. However, it may be insufficient in less competitive industries from the social welfare point of view. In this case, a government subsidy is necessary. We present an analysis of firms' adoption of new technology and government subsidization policy in a Stackelberg duopoly with differentiated goods. The technology itself is free, but each firm must expend a fixed set-up cost, such as training employees. There are several cases related to optimal policies depending on the set-up costs and whether the goods are substitutes or complements. In particular, there are two cases.

1. Social welfare is maximized when only the Stackelberg leader adopts the new technology, but no firm adopts the new technology without a subsidy. Then, the government should subsidize only the leader, which is a discriminatory policy. (Case 5 of Theorem 1 and Case 3-(1)-ii of Theorem 2)

2. Social welfare is maximized when both firms adopt the new technology, but only the leader adopts the new technology without a subsidy. Then, the government should subsidize only the follower. This policy is not discriminatory because adoption is the dominant strategy for the leader. (Case 2 of Theorem 1)
\end{abstract}

Keywords Stackelberg duopoly - Adoption of new technology · Subsidization • Sub-game perfect equilibrium

JEL Classification D43 · L13 · O31

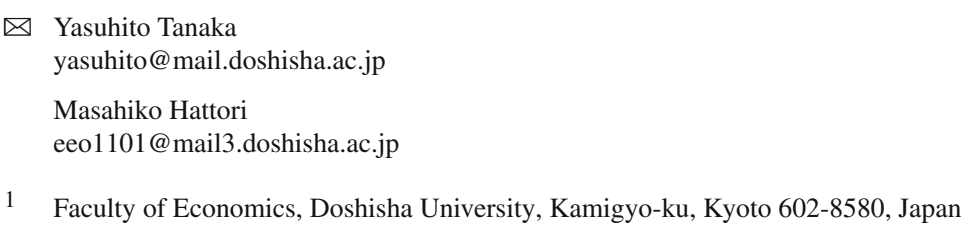




\section{Introduction}

Firms' adoption of new technology is very important for economic growth. However, it may be insufficient in less competitive industries from the social welfare point of view. In this case, a government subsidy is necessary. We present an analysis of firms' adoption of new technology and government subsidization policy in a Stackelberg duopoly with differentiated goods. The technology itself is free, but each firm must expend a fixed set-up cost, such as training employees.

We analyze the following three-stage game ${ }^{1}$.

1. First stage: The government determines the subsidy for each firm.

2. Second stage: The leader decides whether to adopt the new technology and then determines its output.

3. Third stage: The follower decides whether to adopt the new technology and then determines its output.

At the sub-game perfect equilibria, the number of adopting firms decreases from three to zero as the set-up costs increase.

Social welfare is defined as the sum of consumer surplus and firms' profits, which is equal to consumer utility minus production costs, including the new technology set-up costs. Subsidies are financed by lump-sum taxes on consumers, which are not related to the goods produced by firms. Excluding income effects, these taxes do not affect demand for the goods, and are offset by subsidies.

There are several cases for optimal policies depending on the set-up costs and whether the goods produced are substitutes or complements. In particular, we highlight the following cases:

1. Social welfare is maximized when only the Stackelberg leader adopts the new technology, but no firm adopts the new technology without a subsidy. Then, the government should subsidize only the leader, which is a discriminatory policy. (Case 5 of Theorem 1 and Case 3-(1)-ii of Theorem 2)

2. Social welfare is maximized when both firms adopt the new technology, but only the leader adopts the new technology without a subsidy. Then, the government should subsidize only the follower. This policy is not discriminatory because adoption is the dominant strategy for the leader. (Case 2 of Theorem 1)

3. Social welfare is maximized when both firms adopt the new technology, but no firm adopts the new technology without a subsidy. Since adopting a new technology is the best response for the follower when the leader adopts the new technology, the government should subsidize only the leader. This policy is not discriminatory because the follower adopts the new technology without a subsidy. (Case 2-(1)-ii and Case 2-(2)-iii of Theorem 2)

4. Social welfare is maximized when both firms adopt the new technology, but only the follower adopts the new technology without a subsidy. The government should

\footnotetext{
1 Alternatively, we can consider a five-stage game such that 1) the government determines the subsidy for each firm, 2) the leader decides whether to adopt the new technology, 3 ) the follower decides whether to adopt the new technology, 4) the leader determines its output, and 5) the follower determines its output.
} 
subsidize only the leader. This policy is not discriminatory because adopting a new technology is the dominant strategy for the follower. (Case 2-(2)-ii of Theorem 2)

Theorem 1 describes the case where goods are substitutes, and Theorem 2 that where goods are complements. Our model is, at least mathematically, equivalent to a model of technology license with a fixed license fee ${ }^{2}$.

In Sect. 2, we review related literature and present the model in Sect. 3. We analyze the optimal subsidy policy when goods are substitutes and when they are complements in Sects. 4 and 5, respectively.

\section{Related Literature}

Many studies focus on the relationship between a technology licensor and licensee. Contracts vary in terms of royalties, up-front fees, combinations of these two, and auction, which are well discussed (Katz and Shapiro 1985; Kamien and Tauman 1986; Sen and Tauman 2007). Kamien and Tauman (1986) shows that if the licensor lacks production capacity, a fixed fee is better than a royalty, and is also better for consumers. This topic is addressed under Stackelberg oligopoly both when a licensor has production capacity (Wang and Yang 2004; Kabiraj 2005; Filippini 2005) and when it lacks production capacity (Kabiraj 2004). La Manna (1993) analyzes a Cournot oligopoly with a fixed fee under cost asymmetry, and shows that if technologies can be replicated perfectly, a lower-cost firm always has an incentive to transfer its technology. Hence, a Cournot-Nash equilibrium cannot be fully asymmetric, but there exists no non-cooperative Nash equilibrium in pure strategies. On the other hand, using cooperative game theory Watanabe and Muto (2008), analyses bargaining between a licensor with no production capacity and oligopolistic firms. More recent work analyzes market structure and technology improvement. Boone (2001) and Matsumura et. al. (2013), respectively, find a non-monotonic relationship between the intensity of competition and innovation. Additionally, Pal (2010) shows that technology adoption may change the market outcome. Social welfare is larger in Bertrand competition than in Cournot competition. However, if we consider technology adoption, Cournot competition may produce greater social welfare than Bertrand competition in a differentiated goods market. Elberfeld and Nti (2004) examine new technology adoption in an oligopoly with ex-ante uncertainty about the associated variable costs, and shows that if in equilibrium both technologies are employed, a higher level of uncertainty about the new technology increases (decreases) the number of innovating firms and decreases (increases) the product's price if the up-front investment is large (small). Zhang et. al. (2014) analyzes the effect of information spillovers with uncertain R\&D outcomes in a two-stage Cournot oligopoly model where a subset of firms first independently choose between two alternative production technologies before all firms compete in quantity. Hattori and Tanaka (2014) analyzes new technology adoption in a Cournot duopoly with differentiated goods. Liao and Sen (2005) analyzed a situa-

\footnotetext{
2 There are two types of license contract: a fixed fee contract and a royalty contract. Similarly, we can consider a specific or ad-valorem subsidy for new technology instead of a lump-sum subsidy. This is a theme for future research.
} 
tion where an outside or incumbent innovator may use a subsidy as a negative royalty from a licensee with a positive fixed fee. However, they did not consider a government subsidy policy. However, Hattori and Tanaka (2015) analyze government subsidies or taxes for new technology adoption in a Cournot duopoly, and show that if firms produce a homogeneous good, taxation is a better policy than subsidization.

\section{Model}

Consider a Stackelberg duopoly in which two firms, A and B, produce differentiated goods. Firm A is the leader and Firm B is the follower. They consider adopting a new technology from a foreign country. The technology itself is free, but each firm will incur a fixed set-up cost to adopt the new technology, such as for training employees. We denote the outputs of Firms A and B with $x_{A}$ and $x_{B}$, and the prices of their goods by $p_{A}$ and $p_{B}$, respectively. The consumer utility function is:

$$
u=a\left(x_{A}+x_{B}\right)-\frac{1}{2} x_{A}^{2}-b x_{A} x_{B}-\frac{1}{2} x_{B}^{2},
$$

where $a>0$. If goods are substitutes, $0<b<1$; if they are complements, $-1<b<$ 0 . From this utility function, the inverse demand functions of the goods are derived as follows.

$$
p_{A}=a-x_{A}-b x_{B}, p_{B}=a-x_{B}-b x_{A} .
$$

The marginal cost of both firms before adopting the new technology is $c>0$, and zero afterward. The fixed set-up cost to adopt the new technology is $e>0$.

Assumption 1 We assume that $a$ is sufficiently large, and $|b|$ is not so large, such that $a>\frac{c}{1-b}$ is satisfied. For example, $a>2 c$ and $|b|<1 / 2$.

If $|b|$ is large, for example, $b=1$ (the goods are homogeneous), taxation may be a better policy than subsidization, a theme for future research. In this paper, we focus on comparing cases of substitutes and complements, with no taxation case ${ }^{3}$.

If a firm is indifferent as to whether to adopt the new technology, it adopts the new technology.

\section{Case of Substitutes}

\subsection{Firm Behavior}

Assume that goods are substitutes. The profits for Firm A (the leader) and B (the follower) before adopting the new technology are

$$
\pi_{A}=\left(a-x_{A}-b x_{B}\right) x_{A}-c x_{A}, \pi_{B}=\left(a-x_{B}-b x_{A}\right) x_{B}-c x_{B} .
$$

\footnotetext{
3 Hattori and Tanaka (2015) show that taxation is a better policy than subsidization in a Cournot duopoly with a homogeneous good under linear cost functions.
} 
The profits after adoption become

$$
\pi_{A}=\left(a-x_{A}-b x_{B}\right) x_{A}-e, \pi_{B}=\left(a-x_{B}-b x_{A}\right) x_{B}-e .
$$

The conditions to maximize profit when both firms adopt the new technology are

$$
a-\left(2+b \frac{d x_{B}}{d x_{A}}\right) x_{A}-b x_{B}=0, a-2 x_{B}-b x_{A}=0,
$$

where

$$
\frac{d x_{B}}{d x_{A}}=-\frac{b}{2}
$$

This is common to all cases. The condition for Firm A is rewritten as

$$
a-\left(2-\frac{b^{2}}{2}\right) x_{A}-b x_{B}=0 .
$$

The equilibrium outputs are

$$
x_{A}=\frac{2-b}{2\left(2-b^{2}\right)} a, x_{B}=\frac{4-2 b-b^{2}}{4\left(2-b^{2}\right)} a .
$$

The prices of the goods are

$$
p_{A}=\frac{2-b}{4} a, p_{B}=\frac{4-2 b-b^{2}}{4\left(2-b^{2}\right)} a .
$$

The firms' profits are written as

$$
\pi_{A}^{2}=\frac{(2-b)^{2}}{8\left(2-b^{2}\right)} a^{2}-e, \pi_{B}^{2}=\frac{\left(4-2 b-b^{2}\right)^{2}}{16\left(2-b^{2}\right)^{2}} a^{2}-e .
$$

The conditions to maximize profit when no firm adopts the new technology are

$$
a-\left(2-\frac{b^{2}}{2}\right) x_{A}-b x_{B}-c=0, a-2 x_{B}-b x_{A}-c=0 .
$$

The equilibrium outputs are

$$
x_{A}=\frac{2-b}{2\left(a-b^{2}\right)}(a-c), x_{B}=\frac{4-2 b-b^{2}}{4\left(2-b^{2}\right)}(a-c) .
$$

The prices of the goods are

$$
p_{A}=\frac{2-b}{4}(a-c), p_{B}=\frac{4-2 b-b^{2}}{4\left(2-b^{2}\right)}(a-c) .
$$


The firms' profits are written as

$$
\pi_{A}^{0}=\frac{(2-b)^{2}}{8\left(2-b^{2}\right)}(a-c)^{2}, \pi_{B}^{0}=\frac{\left(4-2 b-b^{2}\right)^{2}}{16\left(2-b^{2}\right)^{2}}(a-c)^{2} .
$$

The conditions to maximize profit when only Firm A adopts the new technology are

$$
a-\left(2-\frac{b^{2}}{2}\right) x_{A}-b x_{B}=0, a-2 x_{B}-b x_{A}-c=0
$$

The equilibrium outputs are

$$
x_{A}=\frac{(2-b) a+b c}{2\left(2-b^{2}\right)}, x_{B}=\frac{\left(4-2 b-b^{2}\right) a-\left(4-b^{2}\right) c}{4\left(2-b^{2}\right)} .
$$

The prices of the goods are

$$
p_{A}=\frac{(2-b) a+b c}{4}, p_{B}=\frac{\left(4-2 b-b^{2}\right) a-\left(4-b^{2}\right) c}{4\left(2-b^{2}\right)}+c .
$$

The firms' profits are written as

$$
\pi_{A}^{A}=\frac{[(2-b) a+b c]^{2}}{8\left(2-b^{2}\right)}-e, \pi_{B}^{A}=\frac{\left[\left(4-2 b-b^{2}\right) a-\left(4-b^{2}\right) c\right]^{2}}{16\left(2-b^{2}\right)^{2}} .
$$

Similarly, when only Firm B adopts the new technology, the equilibrium outputs are

$$
x_{A}=\frac{(2-b) a-2 c}{2\left(2-b^{2}\right)}, x_{B}=\frac{\left(4-2 b-b^{2}\right) a+2 b c}{4\left(2-b^{2}\right)} .
$$

The prices of the goods are

$$
p_{A}=\frac{(2-b) a-2 c}{4}+c, p_{B}=\frac{\left(4-2 b-b^{2}\right) a+2 b c}{4\left(2-b^{2}\right)} .
$$

The firms' profits are written as

$$
\pi_{A}^{B}=\frac{[(2-b) a-2 c]^{2}}{8\left(2-b^{2}\right)}, \pi_{B}^{B}=\frac{\left[\left(4-2 b-b^{2}\right) a+2 b c\right]^{2}}{16\left(2-b^{2}\right)^{2}}-e .
$$


Comparing the firms' profits before and after adoption yields

$$
\begin{aligned}
& \pi_{A}^{2}-\pi_{A}^{B}=\frac{(2 a-a b-c) c}{2\left(2-b^{2}\right)}-e, \pi_{A}^{A}-\pi_{A}^{0}=\frac{(2 a+b c-a b-c) c}{2\left(2-b^{2}\right)}-e, \\
& \pi_{B}^{2}-\pi_{B}^{A}=\frac{(2-b)(2+b)\left(8 a-4 a b-2 a b^{2}-4 c+b^{2} c\right) c}{16\left(2-b^{2}\right)^{2}}-e \\
& \pi_{B}^{B}-\pi_{B}^{0}=\frac{(2-b)(2+b)\left(8 a-4 a b-2 a b^{2}+4 b c-4 c+b^{2} c\right) c}{16\left(2-b^{2}\right)^{2}}-e .
\end{aligned}
$$

Let

$$
\begin{aligned}
e_{A}^{2} & =\frac{(2 a-a b-c) c}{2\left(2-b^{2}\right)}, e_{A}^{1}=\frac{(2 a+b c-a b-c) c}{2\left(2-b^{2}\right)}, \\
e_{B}^{2} & =\frac{(2-b)(2+b)\left(8 a-4 a b-2 a b^{2}-4 c+b^{2} c\right) c}{16\left(2-b^{2}\right)^{2}}, \\
e_{B}^{1} & =\frac{(2-b)(2+b)\left(8 a-4 a b-2 a b^{2}+4 b c-4 c+b^{2} c\right) c}{16\left(2-b^{2}\right)^{2}} .
\end{aligned}
$$

Then:

1. If and only if $e \leq e_{B}^{2}$, the best response of Firm B when Firm A adopts the new technology is to adopt the new technology.

2. If and only if $e \leq e_{B}^{1}$, the best response of Firm B when Firm A does not adopt the new technology is to adopt the new technology.

On the other hand, for Firm A:

1. If and only if $e \leq e_{A}^{2}$, the best response of Firm A when Firm B adopts the new technology is to adopt the new technology.

2. If and only if $e \leq e_{A}^{1}$, the best response of Firm A when Firm B does not adopt new technology is to adopt the new technology.

We now find

$$
e_{B}^{1}-e_{B}^{2}=\frac{(2-b)(2+b) b c^{2}}{4\left(2-b^{2}\right)^{2}}>0, e_{A}^{1}-e_{A}^{2}=\frac{b c^{2}}{2\left(2-b^{2}\right)}>0 .
$$

Then, we obtain the following lemma.

Lemma 1 When goods are substitutes;

1. (1) If $e \leq e_{B}^{2}$, new technology adoption is the dominant strategy for Firm $B$.

(2) If $e_{B}^{2}<e \leq e_{B}^{1}$, new technology adoption is the best response for Firm $B$ when Firm A does not adopt, and non-adoption is the best response for Firm B when Firm A adopts the new technology.

(3) If $e>e_{B}^{1}$, non-adoption of the new technology is the dominant strategy for Firm $B$.

2. (1) If $e \leq e_{A}^{2}$, Firm $A$ adopts the new technology whether Firm B's strategy is adoption or non-adoption. 


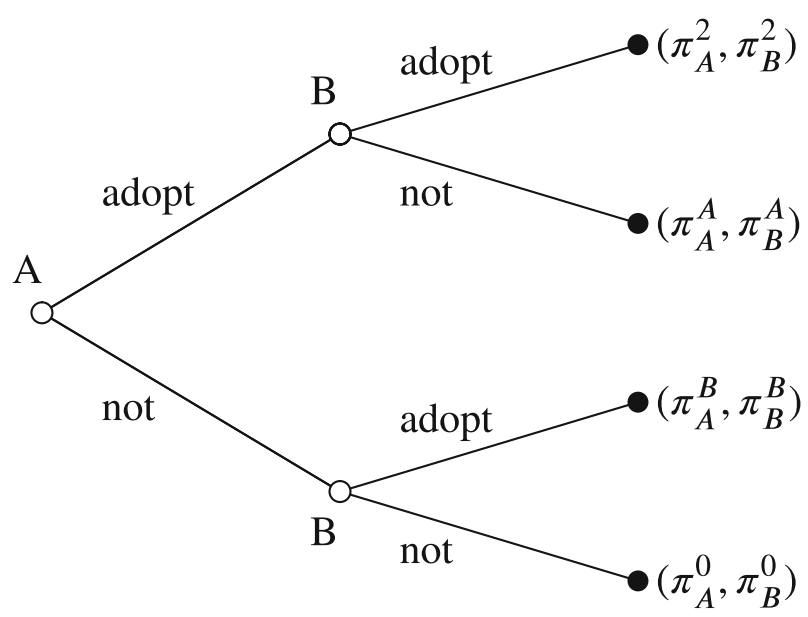

Fig. 1 Game tree

(2) If $e_{A}^{2}<e \leq e_{A}^{1}$, Firm A adopts the new technology when Firm B does not adopt, and it does not adopt the new technology when Firm B adopts.

(3) If e $>e_{A}^{1}$, Firm A does not adopt the new technology whether Firm B's strategy is adoption or non-adoption.

The game is depicted in Fig. 1.

We have

$$
\begin{gathered}
e_{A}^{2}-e_{B}^{1}=\frac{\left(4 a b^{2}-2 a b^{3}+b^{3} c+4 b^{2} c-16 c\right) b c}{16\left(2-b^{2}\right)^{2}}, e_{A}^{2}-e_{B}^{2}=\frac{(4 a-2 a b+b c) b^{3} c}{16\left(2-b^{2}\right)^{2}}, \\
e_{A}^{1}-e_{B}^{1}=\frac{(4 a-2 a b+b c-4 c) b^{3} c}{16\left(2-b^{2}\right)^{2}} .
\end{gathered}
$$

Although $e_{A}^{1}-e_{B}^{1}>0$ and $e_{A}^{2}-e_{B}^{2}>0$ for reasonable values of variables, $e_{A}^{2}-e_{B}^{1}$ may be positive or negative. For example, when $a=10, b=\frac{1}{2}, c=4, e_{A}^{1}-e_{B}^{1}=\frac{8}{49}$, $e_{A}^{2}-e_{B}^{2}=\frac{16}{49}$ and $e_{A}^{2}-e_{B}^{1}=-\frac{104}{49}$; when $a=200, b=\frac{1}{2}, c=4, e_{A}^{1}-e_{B}^{1}=\frac{293}{49}$, $e_{A}^{2}-e_{B}^{2}=\frac{43}{7}$ and $e_{A}^{2}-e_{B}^{1}=\frac{181}{49}$. However, we obtain the same conclusion in both cases.

The sub-game perfect equilibria after the second stage are as follows:

Lemma 2 1. If $e \leq e_{B}^{2}$, both firms adopt the new technology.

2. If $e_{B}^{2}<e \leq e_{A}^{1}$, only Firm A adopts the new technology.

3. If $e>e_{A}^{1}$, no firm adopts the new technology.

Proof See "Appendix 1".

Note that there exists no equilibrium where only Firm B adopts the new technology. 


\subsection{Social Welfare and Policy}

Social welfare is defined as the sum of consumer surplus and firms' profits, which is equal to consumer utility minus production costs, including the set-up costs for the new technology. Subsidies are financed by lump-sum taxes on consumers, which are not related to the goods produced by the firms. Excluding income effects, these taxes do not affect demand for the goods, and are offset by subsidies.

We denote social welfare when both firms adopt the new technology as $W^{2}$, that when only Firm A adopts the new technology as $W^{A}$, that when only Firm B adopts the new technology as $W^{B}$, and that when no firm adopts the new technology as $W^{0}$. Then, we have

$$
\begin{aligned}
W^{2} & =a\left(x_{A}+x_{B}\right)-\frac{1}{2} x_{A}^{2}-b x_{A} x_{B}-\frac{1}{2} x_{B}^{2}-2 e \\
& =\frac{a^{2}\left(3 b^{4}+28 b^{3}-48 b^{2}-64 b+96\right)}{32\left(2-b^{2}\right)^{2}}-2 e,
\end{aligned}
$$

$$
\begin{gathered}
W^{A}=a x_{A}+(a-c) x_{B}-\frac{1}{2} x_{A}^{2}-b x_{A} x_{B}-\frac{1}{2} x_{B}^{2}-e \\
=\frac{1}{32\left(2-b^{2}\right)^{2}}\left(3 b^{4} c^{2}-28 b^{2} c^{2}+48 c^{2}-6 a b^{4} c-28 a b^{3} c+56 a b^{2} c+64 a b c\right. \\
\left.-96 a c+3 a^{2} b^{4}+28 a^{2} b^{3}-48 a^{2} b^{2}-64 a^{2} b+96 a^{2}\right)-e \\
W^{B}=(a-c) x_{A}+a x_{B}-\frac{1}{2} x_{A}^{2}-b x_{A} x_{B}-\frac{1}{2} x_{B}^{2}-e \\
=\frac{1}{32\left(2-b^{2}\right)^{2}}\left(-20 b^{2} c^{2}+48 c^{2}-28 a b^{3} c+40 a b^{2} c+64 a b c\right. \\
\left.\quad-96 a c+3 a^{2} b^{4}+28 a^{2} b^{3}-48 a^{2} b^{2}-64 a^{2} b+96 a^{2}\right)-e
\end{gathered}
$$

and

$$
\begin{aligned}
W^{0} & =(a-c)\left(x_{A}+x_{B}\right)-\frac{1}{2} x_{A}^{2}-b x_{A} x_{B}-\frac{1}{2} x_{B}^{2} \\
& =\frac{\left(3 b^{4}+28 b^{3}-48 b^{2}-64 b+96\right)(a-c)^{2}}{32\left(2-b^{2}\right)^{2}} .
\end{aligned}
$$

We see that

$$
W^{A}-W^{B}=\frac{(2 a-c)\left(8-3 b^{2}\right) b^{2} c}{32\left(2-b^{2}\right)^{2}}>0 .
$$

Let

$$
e^{20}=\frac{W^{2}+2 e-W^{0}}{2}=\frac{(2 a-c)\left(3 b^{4}+28 b^{3}-48 b^{2}-64 b+96\right) c}{64\left(2-b^{2}\right)^{2}},
$$




$$
\begin{aligned}
e^{A 0} & =W^{A}-W^{0}+e=\frac{\left(7 a b^{3}-10 a b^{2}-16 a b+24 a-7 b^{3} c+5 b^{2} c+16 b c-12 c\right) c}{8\left(2-b^{2}\right)^{2}}, \\
e^{2 A} & =W^{2}-W^{A}+e=\frac{\left(6 a b^{4}+28 a b^{3}-56 a b^{2}-64 a b+96 a-3 b^{4} c+28 b^{2} c-48 c\right) c}{32\left(2-b^{2}\right)^{2}}, \\
e^{B 0} & =W^{B}-W^{0}+e \\
& =\frac{\left(6 a b^{4}+28 a b^{3}-56 a b^{2}-64 a b+96 a-3 b^{4} c-28 b^{3} c+28 b^{2} c+64 b c-48 c\right) c}{32\left(2-b^{2}\right)^{2}}, \\
& e^{2 B}=W^{2}-W^{B}+e=\frac{\left(7 a b^{3}-10 a b^{2}-16 a b+24 a+5 b^{2} c-12 c\right) c}{8\left(2-b^{2}\right)^{2}} .
\end{aligned}
$$

All are positive under Assumption 1. We have

$$
\begin{aligned}
e^{2 A}-e^{2 B} & =-\frac{(2 a-c)\left(8-3 b^{2}\right) b^{2} c}{32\left(2-b^{2}\right)^{2}}, \\
e^{2 A}-e^{20} & =-\frac{\left(16 a b-6 a b^{3}+3 b^{3} c-28 b^{2} c-8 b c+64 c\right) b c}{64\left(2-b^{2}\right)^{2}}, \\
e^{2 A}-e^{B 0} & =\frac{\left(7 b^{2}-16\right) b c^{2}}{8\left(2-b^{2}\right)^{2}}, \\
e^{2 A}-e^{A 0} & =-\frac{\left(16 a b-6 a b^{3}+3 b^{3} c-28 b^{2} c-8 b c+64 c\right) b c}{32\left(2-b^{2}\right)^{2}}, \\
e^{2 B}-e^{A 0} & =\frac{\left(7 b^{2}-16\right) b c^{2}}{8\left(2-b^{2}\right)^{2}}, \\
e^{20}-e^{A 0} & =-\frac{\left(16 a b-6 a b^{3}+3 b^{3} c-28 b^{2} c-8 b c+64 c\right) b c}{64\left(2-b^{2}\right)^{2}}, \\
e^{B 0}-e^{A 0} & =-\frac{(2 a-c)\left(8-3 b^{2}\right) b^{2} c}{32\left(2-b^{2}\right)^{2}},
\end{aligned}
$$

For reasonable values of variables, all are negative. Therefore,

$$
e^{2 A}<e^{2 B}, e^{20}, e^{B 0}<e^{A 0}
$$

Thus, from $W^{A}>W^{B}$ we obtain the following lemma.

Lemma 3 1. If $e \leq e^{2 A}, W^{2}$ is the maximum, then new technology adoption by both firms is optimal.

2. If $e^{2 A}<e \leq e^{A 0}, W^{A}$ is the maximum, then new technology adoption by only Firm A is optimal.

3. If $e>e^{A 0}, W^{0}$ is the maximum, then new technology adoption by no firm is optimal. 
We now have

$$
\begin{aligned}
& e^{2 A}-e_{A}^{1} \\
& =\frac{\left(-3 b^{4} c+16 b^{3} c+12 b^{2} c-32 b c-16 c+6 a b^{4}+12 a b^{3}-24 a b^{2}-32 a b+32 a\right) c}{32\left(2-b^{2}\right)^{2}}>0 .
\end{aligned}
$$

Therefore, we obtain the following theorem.

Theorem 1 When goods are substitutes, the optimal policies are as follows:

1. If $e \leq e_{B}^{2}$, the government should do nothing.

2. If $e_{B}^{2}<e \leq e_{A}^{2}$, the government should subsidize only Firm $\mathrm{B}$, at a level greater than $e-e_{B}^{2}$. Since Firm A adopts the new technology without a subsidy in this case, the policy is not discriminatory.

3. If $e_{A}^{2}<e \leq e_{A}^{1}$, the government should subsidize both firms at a level greater than $e-e_{A}^{2}$ for Firm $A$ and $e-e_{B}^{2}$ for Firm $B$.

4. If $e_{A}^{1}<e \leq e^{2 A}$, the government should subsidize both firms at a level greater than $e-e_{A}^{2}$ for Firm $A$ and $e-e_{B}^{2}$ for Firm $B$.

5. If $e^{2 A}<e \leq e^{A 0}$, the government should subsidize only Firm A, at a level greater than $e-e_{A}^{1}$. Because Firm $B$ does not adopt the new technology in this case, this policy is discriminatory and favors Firm A, the leader.

6. If $e>e^{A 0}$, the government should do nothing.

\section{Proof See "Appendix 2".}

The following table summarizes the results of this theorem.

1. $e \leq e_{B}^{2}$

$W^{2}$ is optimal,both firms adopt the new technology, and the government does nothing.

3. $e_{A}^{2}<e \leq e_{A}^{1}$

$W^{2}$ is optimal, only Firm A adopts the new technology, and the government subsidizes both firms.

5. $e^{2 A}<e \leq e^{A 0}$

$W^{A}$ is optimal, no firm adopts the new technology, and the government subsidizes Firm A.
2. $e_{B}^{2}<e \leq e_{A}^{2}$

$W^{2}$ is optimal, only Firm A adopts the new technology, and the government subsidizes Firm B.

4. $e_{A}^{1}<e \leq e^{2 A}$

$W^{2}$ is optimal, no firm adopts the new technology, and the government subsidizes both firms.

6. $e>e^{A 0}$

$W^{0}$ is optimal, no firm adopts the new technology, and the government does nothing. 


\section{Case of Complements}

\subsection{Firm Behavior}

Assume that goods are complements. Similar to the previous section, let

$$
\begin{aligned}
& e_{A}^{2}=\pi_{A}^{2}-\pi_{A}^{B}=\frac{(2 a-a b-c) c}{2\left(2-b^{2}\right)}, e_{A}^{1}=\pi_{A}^{A}-\pi_{A}^{0}=\frac{(2 a-a b-c+b c) c}{2\left(2-b^{2}\right)}, \\
& e_{B}^{2}=\pi_{B}^{2}-\pi_{B}^{A}=\frac{(2-b)(2+b)\left(8 a-4 a b-2 a b^{2}-4 c+b^{2} c\right) c}{16\left(2-b^{2}\right)^{2}}
\end{aligned}
$$

and

$$
e_{B}^{1}=\pi_{B}^{B}-\pi_{B}^{0}=\frac{(2-b)(2+b)\left(8 a-4 a b-2 a b^{2}+4 b c-4 c+b^{2} c\right) c}{16\left(2-b^{2}\right)^{2}} .
$$

Since $b<0$

$$
e_{B}^{1}-e_{B}^{2}=\frac{(2-b)(2+b) b c^{2}}{4\left(2-b^{2}\right)^{2}}<0, e_{A}^{1}-e_{A}^{2}=\frac{b c^{2}}{2\left(2-b^{2}\right)}<0,
$$

we obtain the following lemma.

Lemma 4 When goods are complements:

1. (1) If $e \leq e_{B}^{1}$, new technology adoption is the dominant strategy for Firm $B$.

(2) If $e_{B}^{1}<e \leq e_{B}^{2}$, new technology adoption is the best response for Firm $B$ when Firm A adopts the new technology, and non-adoption is the best response for Firm $B$ when Firm A does not adopt.

(3) If $e>e_{B}^{2}$, non-adoption is the dominant strategy for Firm $B$.

2. (1) If $e \leq e_{A}^{1}$, Firm A adopts the new technology whether Firm B's strategy is adoption or non-adoption.

(2) If $e_{A}^{1}<e \leq e_{A}^{2}$, Firm A adopts the new technology when Firm B adopts, and it does not adopt when Firm $B$ does not adopt.

(3) If $e>e_{A}^{2}$, Firm A does not adopt the new technology whether Firm B's strategy is adoption or non-adoption.

We have

$$
\begin{gathered}
e_{A}^{2}-e_{B}^{1}=\frac{\left(4 a b^{2}-2 a b^{3}+b^{3} c+4 b^{2} c-16 c\right) b c}{16\left(2-b^{2}\right)^{2}}, e_{A}^{2}-e_{B}^{2}=\frac{(4 a-2 a b+b c) b^{3} c}{16\left(2-b^{2}\right)^{2}} \\
e_{A}^{1}-e_{B}^{1}=\frac{(4 a-2 a b+b c-4 c) b^{3} c}{16\left(2-b^{2}\right)^{2}}
\end{gathered}
$$

Since $b<0, e_{A}^{1}-e_{B}^{1}<0$ and $e_{A}^{2}-e_{B}^{2}<0$ for reasonable values of variables, though $e_{A}^{2}-e_{B}^{1}$ may be positive or negative. For example, when $a=10, b=-\frac{1}{2}, c=4$, 
$e_{A}^{1}-e_{B}^{1}=-\frac{16}{49}, e_{A}^{2}-e_{B}^{2}=-\frac{24}{49}$ and $e_{A}^{2}-e_{B}^{1}=\frac{96}{49}$; when $a=200, b=-\frac{1}{2}, c=4$, $e_{A}^{1}-e_{B}^{1}=-\frac{491}{49}, e_{A}^{2}-e_{B}^{2}=-\frac{499}{49}$ and $e_{A}^{2}-e_{B}^{1}=-\frac{379}{49}$. The sub-game perfect equilibria after the second stage depends on whether $e_{A}^{2}>e_{B}^{1}$ or $e_{A}^{2}<e_{B}^{1}$. We can show the following lemma.

Lemma 5 1. If $e \leq e_{A}^{1}$, both firms adopt the new technology.

2. If $e_{A}^{1}<e \leq e_{B}^{2}$, there are two cases:

(1) If $e_{A}^{2}>e_{B}^{1}$, there are three sub-cases:

i. If $e_{A}^{1}<e \leq e_{B}^{1}$, both firms adopt the new technology.

ii. If $e_{B}^{1}<e \leq e_{A}^{2}$, both firms adopt the new technology.

iii. If $e_{A}^{2}<e \leq e_{B}^{2}$, no firm adopts the new technology.

(2) If $e_{A}^{2}<e_{B}^{1}$, there are three sub-cases:

i. If $e_{A}^{1}<e \leq e_{A}^{2}$, both firms adopt the new technology.

ii. If $e_{A}^{2}<e \leq e_{B}^{1}$, only Firm $B$ adopts the new technology.

iii. If $e_{B}^{1}<e \leq e_{B}^{2}$, no firm adopts the new technology.

3. If $e>e_{B}^{2}$, no firm adopts the new technology.

Proof See "Appendix 3".

Note that there exists no equilibrium where only Firm A (the leader) adopts the new technology.

\subsection{Social Welfare and Policy}

Similar to the case of substitutes, we see:

$$
W^{A}-W^{B}=\frac{(2 a-c)\left(8-3 b^{2}\right) b^{2} c}{32\left(2-b^{2}\right)^{2}}>0 .
$$

Let

$$
\begin{aligned}
e^{20} & =\frac{W^{2}+2 e-W^{0}}{2}=\frac{(2 a-c)\left(3 b^{4}+28 b^{3}-48 b^{2}-64 b+96\right) c}{64\left(2-b^{2}\right)^{2}} \\
e^{A 0} & =W^{A}-W^{0}+e=\frac{\left(7 a b^{3}-10 a b^{2}-16 a b+24 a-7 b^{3} c+5 b^{2} c+16 b c-12 c\right) c}{8\left(2-b^{2}\right)^{2}}, \\
e^{2 A} & =W^{2}-W^{A}+e=\frac{\left(6 a b^{4}+28 a b^{3}-56 a b^{2}-64 a b+96 a-3 b^{4} c+28 b^{2} c-48 c\right) c}{32\left(2-b^{2}\right)^{2}}, \\
e^{B 0} & =W^{B}-W^{0}+e \\
& =\frac{\left(6 a b^{4}+28 a b^{3}-56 a b^{2}-64 a b+96 a-3 b^{4} c-28 b^{3} c+28 b^{2} c+64 b c-48 c\right) c}{32\left(2-b^{2}\right)^{2}}, \\
& e^{2 B}=W^{2}-W^{B}+e=\frac{\left(7 a b^{3}-10 a b^{2}-16 a b+24 a+5 b^{2} c-12 c\right) c}{8\left(2-b^{2}\right)^{2}} .
\end{aligned}
$$


All are positive under Assumption 1. Comparing them;

$$
\begin{aligned}
e^{2 A}-e^{2 B} & =-\frac{(2 a-c)\left(8-3 b^{2}\right) b^{2} c}{32\left(2-b^{2}\right)^{2}}, \\
e^{2 A}-e^{20} & =-\frac{\left(16 a b-6 a b^{3}+3 b^{3} c-28 b^{2} c-8 b c+64 c\right) b c}{64\left(2-b^{2}\right)^{2}}, \\
e^{2 A}-e^{B 0} & =\frac{\left(7 b^{2}-16\right) b c^{2}}{8\left(2-b^{2}\right)^{2}}, \\
e^{2 A}-e^{A 0} & =-\frac{\left(16 a b-6 a b^{3}+3 b^{3} c-28 b^{2} c-8 b c+64 c\right) b c}{32\left(2-b^{2}\right)^{2}}, \\
e^{2 B}-e^{A 0} & =\frac{\left(7 b^{2}-16\right) b c^{2}}{8\left(2-b^{2}\right)^{2}}, \\
e^{20}-e^{A 0} & =-\frac{\left(16 a b-6 a b^{3}+3 b^{3} c-28 b^{2} c-8 b c+64 c\right) b c}{64\left(2-b^{2}\right)^{2}}, \\
e^{B 0}-e^{A 0} & =-\frac{(2 a-c)\left(8-3 b^{2}\right) b^{2} c}{32\left(2-b^{2}\right)^{2}},
\end{aligned}
$$

For reasonable values of variables,

$$
e^{2 A}-e^{2 B}<0, e^{2 A}-e^{B 0}>0, e^{2 B}-e^{A 0}>0, e^{B 0}-e^{A 0}<0 .
$$

However, $e^{2 A}-e^{20}, e^{2 A}-e^{A 0}$ and $e^{20}-e^{A 0}$ may be positive or negative. Since $e^{20}=\frac{e^{2 A}+e^{A 0}}{2}$, there are two cases:

1. $e^{2 A} \leq e^{20} \leq e^{A 0}$.

2. $e^{A 0}<e^{20}<e^{2 A}$.

Thus, we obtain the following lemma.

Lemma 6 1. When $e^{2 A} \leq e^{20} \leq e^{A 0}$ :

(1) If $e \leq e^{2 A}, W^{2}$ is the maximum, then new technology adoption for both firms is optimal.

(2) If $e^{2 A}<e \leq e^{A 0}, W^{A}$ is the maximum, then new technology adoption by only Firm A (the leader) is optimal.

(3) If $e>e^{A 0}, W^{0}$ is the maximum, then new technology adoption by no firm is optimal.

2. When $e^{A 0}<e^{20}<e^{2 A}$ :

(1) If $e \leq e^{20}, W^{2}$ is the maximum, then new technology adoption by both firms is optimal.

(2) If $e>e^{20}, W^{0}$ is the maximum, then new technology adoption by no firm is optimal. 
We now have:

$$
\begin{aligned}
& e^{2 A}-e_{B}^{2}=\frac{\left(2 a b^{4}+20 a b^{3}-24 a b^{2}-32 a b+32 a-b^{4} c+12 b^{2} c-16 c\right) c}{32\left(2-b^{2}\right)^{2}}>0, \\
& e^{A 0}-e_{B}^{2} \\
& =\frac{\left(16 a-2 a b^{4}+10 a b^{3}-4 a b^{2}-16 a b+b^{4} c-14 b^{3} c+2 b^{2} c+32 b c-8 c\right) c}{16\left(2-b^{2}\right)^{2}}>0 .
\end{aligned}
$$

Therefore, we obtain the following theorem.

Theorem 2 When goods are complements, the optimal policies are as follows:

1. If $e \leq e_{A}^{1}$, the government should do nothing.

2. If $e_{A}^{1}<e \leq e_{B}^{2}$, there are two cases:

(1) If $e_{A}^{2}>e_{B}^{1}$, there are two sub-cases:

i. If $e_{A}^{1}<e \leq e_{A}^{2}$, the government should do nothing.

ii. If $e_{A}^{2}<e \leq e_{B}^{2}$, the government should subsidize only Firm A. The level of the subsidy is $e-e_{A}^{2}$. Since Firm B adopts new technology at the equilibrium without subsidy, this policy is not discriminatory.

(2) If $e_{A}^{2}<e_{B}^{1}$, there are three sub-cases.

i. If $e_{A}^{1}<e \leq e_{A}^{2}$, the government should do nothing.

ii. If $e_{A}^{2}<e \leq e_{B}^{1}$, the government should subsidize only Firm A at a level equal to $e-e_{A}^{2}$. Since Firm B adopts the new technology at the equilibrium without subsidy, this policy is not discriminatory.

iii. If $e_{B}^{1}<e \leq e_{B}^{2}$, the government should subsidize only Firm A at a level equal to $e-e_{A}^{2}$. Since Firm $B$ adopts the new technology at the equilibrium without subsidy, this policy is not discriminatory.

3. If $e>e^{2 B}$, there are two cases:

(1) If $e^{2 A} \leq e^{20} \leq e^{A 0}$, there are three sub-cases:

i. If $e_{B}^{2}<\bar{e} \leq e^{2 A}$, the government should subsidize both firms at levels equal to $e-e_{A}^{2}$ and $e-e_{B}^{2}$ for Firm $A$ and $B$, respectively.

ii. If $e^{2 A}<e \leq e^{A 0}$, the government should subsidize only Firm $\mathrm{A}$ at a level equal to $e-e_{A}^{1}$. Since Firm $B$ does not adopt the new technology at the equilibrium, this policy is discriminatory.

iii. If $e>e^{A 0}$, the government should do nothing.

(2) If $e^{A 0}<e^{20}<e^{2 A}$, there are two sub-cases:

i. If $e_{B}^{2}<e \leq e^{20}$, the government should subsidize both firms at levels equal to $e-e_{A}^{2}$ and $e-e_{B}^{2}$ for Firm $A$ and $B$, respectively.

ii. If $e>e^{20}$, the government should do nothing.

Proof See "Appendix 4".

The following table summarizes the results of this theorem. 
1. $e \leq e_{A}^{1}$

$W^{2}$ is optimal, both firms adopt the new technology, and the government does nothing.

2. (1) ii. $e_{A}^{2}>e_{B}^{1}, e_{A}^{2}<e \leq e_{B}^{2}$

$W^{2}$ is optimal, no firm adopts the new technology, and the government subsidizes Firm A; then Firm B also adopts the new technology.

2. (2) ii. $e_{A}^{2}<e_{B}^{1}, e_{A}^{2}<e \leq e_{B}^{1}$

$W^{2}$ is optimal, only Firm $B$ adopts the new technology, and the government subsidizes Firm A.

3. (1) i. $e^{2 A} \leq e^{20} \leq e^{A 0}, e_{B}^{2}<e \leq e^{2 A}$

$W^{2}$ is optimal, no firm adopts the new technology, and the government subsidizes both firms.

3. (1) iii. $e^{2 A} \leq e^{20} \leq e^{A 0}, e>e^{A 0}$

$W^{0}$ is optimal, no firm adopts the new technology, and the government does nothing.

3. (2) ii. $e^{A 0} \leq e^{20} \leq e^{2 A}, e>e^{20}$

$W^{0}$ is optimal, no firm adopts the new technology, and the government does nothing.
2. (1) i. $e_{A}^{2}>e_{B}^{1}, e_{A}^{1}<e \leq e_{A}^{2}$

$W^{2}$ is optimal, both firms adopt the new

technology, and the government does nothing.

2. (2) i. $e_{A}^{2}<e_{B}^{1}, e_{A}^{1}<e \leq e_{A}^{2}$

$W^{2}$ is optimal, both firms adopt the new technology, and the government does nothing.

2. (2) iii. $e_{A}^{2}<e_{B}^{1}, e_{B}^{1}<e \leq e_{B}^{2}$

$W^{2}$ is optimal, no firm adopts the new technology, and the government subsidizes Firm A; then Firm B also adopts the new technology.

3. (1) ii. $e^{2 A} \leq e^{20} \leq e^{A 0}, e^{2 A}<e \leq e^{A 0}$

$W^{A}$ is optimal, no firm adopts the new technology, and the government subsidizes Firm A.

3. (2) i. $e^{A 0}<e^{20}<e^{2 A}, e_{B}^{2}<e \leq e^{20}$

$W^{2}$ is optimal, no firm adopts the new technology, and the government subsidizes both firms.

\section{Concluding Remarks}

In this paper, we analyzed optimal subsidization policies for new technology adoption in a Stackelberg duopoly. However, sub-game perfect equilibria and optimal policies are not simple, and depend on the magnitude of the set-up costs and whether the firms produce substitute or complementary goods. In our model, firms' incentives to adopt new technology are often insufficient, and in which case the government should subsidize firms.

We assumed linear demand and cost functions, though would like to generalize the results to general demand and cost functions.

\section{Appendix 1: Proof of Lemma 2}

1. In this case, new technology adoption is the dominant strategy for both firms.

2. When $e_{A}^{2}-e_{B}^{1}>0$, there are three sub-cases:

(1) $e_{B}^{2}<e \leq e_{B}^{1}$. Then, adoption is the dominant strategy for Firm A, and nonadoption is the best response for Firm B to Firm A's adoption.

(2) $e_{B}^{1}<e \leq e_{A}^{2}$. Then, adoption is the dominant strategy for Firm A, and nonadoption is the dominant strategy for Firm B.

(3) $e_{A}^{2}<e \leq e_{A}^{1}$. Then, adoption is the best response for Firm A to non-adoption by Firm B, and non-adoption is the dominant strategy for Firm B.

When $e_{A}^{2}-e_{B}^{1}<0$, there are three sub-cases: 
(1) $e_{B}^{2}<e \leq e_{A}^{2}$. Then, adoption is the dominant strategy for Firm A, and nonadoption is the best response for Firm B to Firm A's adoption.

(2) $e_{A}^{2}<e \leq e_{B}^{1}$. Then, adoption is the best response for Firm A to non-adoption by Firm B, and non-adoption is the best response for Firm B to Firm A's adoption. On the other hand, non-adoption is the best response for Firm A to Firm B's adoption, and adoption is the best response for Firm B to nonadoption by Firm A. Thus, there are two Nash equilibria: a state where only Firm A adopts the new technology and the other where only Firm B adopts the new technology. The difference between Firm A's profit when it adopts the new technology and that when Firm B adopts the new technology is

$$
\pi_{A}^{A}-\pi_{A}^{B}=\frac{(2-b)(2+b) c(2 a-c)}{8\left(2-b^{2}\right)}-e .
$$

Comparing $\frac{(2-b)(2+b) c(2 a-c)}{8\left(2-b^{2}\right)}$ with $e_{B}^{1}$,

$$
\frac{(2-b)(2+b) c(2 a-c)}{8\left(2-b^{2}\right)}-e_{B}^{1}=\frac{(2-b)(2+b)(b c-4 c-2 a b+4 a) b c}{16\left(2-b^{2}\right)^{2}}>0 .
$$

Thus, Firm A chooses to adopt the new technology in the second stage, and only Firm A adopts the new technology at the sub-game perfect equilibrium.

(3) $e_{B}^{1}<e \leq e_{A}^{1}$. Then, adoption is the best response for Firm $A$ to non-adoption by Firm B, and non-adoption is the dominant strategy for Firm B.

3. In this case, non-adoption is the dominant strategy for both firms.

\section{Appendix 2: Proof of Theorem 1}

1. When $W^{2}$ is optimal, both firms adopt the new technology without a subsidy, and the government should do nothing.

2. In this case, $W^{2}$ is optimal; however, only Firm A adopts the new technology without a subsidy. Since $e \leq e_{A}^{2}$, Firm A adopts the new technology without a subsidy. The government should subsidize Firm B at a level greater than $e-e_{B}^{2}$.

3. When $W^{2}$ is optimal, only Firm A adopts the new technology without a subsidy. The government should subsidize both firms at levels greater than $e-e_{A}^{2}$ for Firm $\mathrm{A}$ and $e-e_{B}^{2}$ for Firm B. Since $e_{A}^{2}>e_{B}^{2}$, we have $e-e_{A}^{2}<e-e_{B}^{2}$. Since $e_{A}^{2}<e \leq e_{A}^{1}$, if the government subsidizes only Firm B, then Firm A does not adopt the new technology. Thus, the government should subsidize both firms.

4. When $W^{2}$ is optimal, no firm adopts the new technology without a subsidy. The government should thus subsidize both firms at levels greater than $e-e_{A}^{2}$ for Firm A and $e-e_{B}^{2}$ for Firm B. Because $e_{A}^{2}>e_{B}^{2}$, we have $e-e_{A}^{2}<e-e_{B}^{2}$.

5. When $W^{A}$ is optimal, no firm adopts the new technology without a subsidy. The government should subsidize one firm, either Firm A or Firm B. However, since $W^{A}>W^{B}$, the government should subsidize only Firm $A$ at a level greater than $e-e_{A}^{1}$. 
6. When $W^{0}$ is optimal, no firm adopts the new technology without a subsidy, and the government should do nothing.

\section{Appendix 3: Proof of Lemma 5}

1. Adopting the new technology is the dominant strategy for both firms.

2. (1) i. When adoption is the dominant strategy for Firm B and adoption is the best response for Firm A when Firm B adopts, both firms adopt the new technology.

ii. When adoption is the best response for both firms when the rival adopts the new technology, and non-adoption is the best response for both firms when the rival does not adopt, there are two equilibria. In the first, both firms adopt the new technology; in the second, neither firm adopts the new technology. Comparing the profit of Firm A (the leader) when both firms adopt the new technology and that when no firm adopts yields

$$
\pi_{A}^{2}-\pi_{A}^{0}=\frac{(2 a-c)(2-b)^{2} c}{8\left(2-b^{2}\right)}>0 .
$$

Therefore, Firm A chooses to adopt the new technology, and both firms adopt the new technology at the sub-game perfect equilibrium.

iii. When non-adoption is the dominant strategy for Firm A and non-adoption is the best response for Firm B when Firm A does not adopt, neither firm adopts the new technology.

(2) i. When adoption is the dominant strategy for Firm B, and adoption is the best response for Firm A when Firm B adopts. both firms adopt the new technology.

ii. When adoption is the dominant strategy for Firm B, and non-adoption is the dominant strategy for Firm A, only Firm B adopts the new technology.

iii. When non-adoption is the dominant strategy for Firm A, and non-adoption is the best response for Firm B when Firm A does not adopt, no firm adopts the new technology.

3. In the final case, non-adoption of the new technology is the dominant strategy for both firms.

\section{Appendix 4: Proof of Theorem 2}

1. When $W^{2}$ is optimal and both firms adopt the new technology without a subsidy, the government should do nothing.

2. (1) i. When $W^{2}$ is optimal and both firms adopt the new technology without a subsidy, the government should do nothing.

ii. When $W^{2}$ is optimal and no firm adopts the new technology without a subsidy, the government should subsidize only Firm $A$ at a level equal to $e-e_{A}^{2}$ because adoption is the best response for Firm B when Firm A adopts. 
(2) i. When $W^{2}$ is optimal and both firms adopt the new technology without a subsidy, the government should do nothing.

ii. When $W^{2}$ is optimal, but only Firm B adopts the new technology without a subsidy because it is the dominant strategy for Firm B, the government should subsidize only Firm A.

iii. When $W^{2}$ is optimal, but no firm adopts the new technology, the government should subsidize only Firm A because new technology adoption is the best response for Firm B when Firm A adopts.

3. (1) i. When $W^{2}$ is optimal, but no firm adopts the new technology without a subsidy, and non-adoption is the dominant strategy for both firms, the government should subsidize both firms.

ii. When $W^{A}$ is optimal, but no firm adopts the new technology without a subsidy, the government should subsidize only Firm A.

iii. When $W^{0}$ is optimal and no firm adopts the new technology without a subsidy, the government should do nothing.

(2) i. When $W^{2}$ is optimal, but no firm adopts the new technology without a subsidy, and non-adoption is the dominant strategy for both firms, the government should subsidize both firms.

ii. If $e>e^{20}, W^{0}$ is optimal and no firm adopts the new technology without a subsidy, and the government should do nothing.

\section{References}

Boone J (2001) Intensity of competition and the incentive to innovate. Int J Indus Organ 19:705-726

Elberfeld W, Nti KO (2004) Oligopolistic competition and new technology adoption under uncertainty. J Econ 82:105-121

Filippini L (2005) Licensing contract in a Stackelberg model. Manch. Sch. 73:582-598

Hattori M, Tanaka Y (2014) Incentive for adoption of new technology in duopoly under absolute and relative profit maximization. Econ Bull 34:2051-2059

Hattori M, Tanaka Y (2015) Subsidy or tax policy for new technology adoption in duopoly with quadratic and linear cost functions. Econ Bull 35:1423-1433

Kabiraj T (2004) Patent licensing in a leadership structure. Manch Sch 72:188-205

Kabiraj T (2005) Technology transfer in a Stackelberg structure: licensing contracts and welfare. Manch Sch 73:1-28

Kamien T, Tauman Y (1986) Fees versus royalties and the private value of a patent. Quart J Econ 101:471492

Katz M, Shapiro C (1985) On the licensing of innovations. Rand J Econ 16:504-520

La Manna M (1993) Asymmetric oligopoly and technology transfers. Econ J 103:436-443

Liao C-H, Sen D (2005) Subsidy in licensing: optimality and welfare implication. Manch Sch 73:281-299

Matsumura T, Matsushima N, Cato S (2013) Competitiveness and R\&D competition revisited. Econ Model 31:541-547

Pal R (2010) Technology adoption in a differentiated duopoly: cournot versus Bertrand. Res Econ 64:128136

Sen D, Tauman Y (2007) General licensing schemes for a cost-reducing Innovation. Games Econ Behav 59:163-186

Wang XH, Yang BZ (2004) On technology licensing in a Stackelberg duopoly. Aust Econ Papers 43:448-458

Watanabe N, Muto S (2008) Stable profit sharing in a patent licensing game: general bargaining outcomes. Int J Game Theory 37:505-523

Zhang Y, Mei S, Zhong W (2014) New technology adoption in a Cournot oligopoly with spillovers. J Econ 112:115-136 